Title:

Development of Structural Materials Exhibiting Dielectric and Magnetic Loss at Radio Frequencies

Author(s):

Joseph R. Duke, Jr., MST-7

Wencos

$0 C 111325$

OSTI

Paul G. Apen, MST

Mark Hoisington, Univ. of Washington

Submitted to:

DOE Office of Scientific and Technical Information (OSTI)

DISTRIBUTION OF THIS DOCUMENT IS UNLMITED
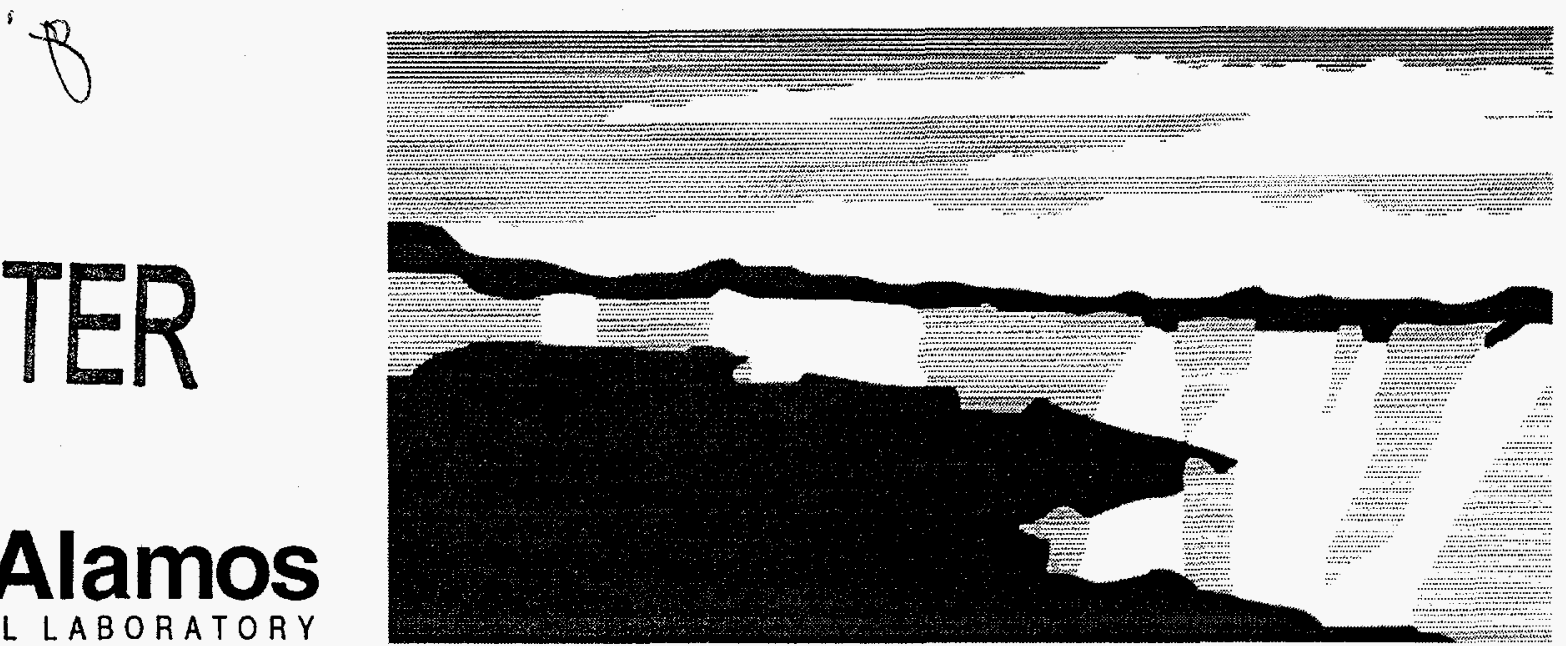

Los Alamos National Laboratory, an attirmative action/equal opportunity employer, is operated by the University of California for the U.S. Department of Energy under contract W-7405-ENG-36. By acceptance of this article, the publisher recognizes that the U.S. Government retains a nonexclusive, royaltyfree license to publish or reproduce the published form of this contribution, or to allow others to do so, for U.S. Government purposes. The Los Alamos National Laboratory requests that the publisher identify this article as work performed under the auspices of the U.S. Department of Energy. 


\section{DISCLAIMER}

This report was prepared as an account of work sponsored by an agency of the United States Government. Neither the United States Government nor any agency thereof, nor any of their employees, makes any warranty, express or implied, or assumes any legal liability or responsibility for the accuracy, completeness, or usefulness of any information, apparatus, product, or process disclosed, or represents that its use would not infringe privately owned rights. Reference herein to any specific commercial product, process, or service by trade name, trademark, manufacturer, or otherwise does not necessarily constitute or imply its endorsement, recommendation, or favoring by the United States Government or any agency thereof. The views and opinions of authors expressed herein do not necessarily state or reflect those of the United States Government or any agency thereof. 


\section{DISCLAIMER}

Portions of this document may be illegible in electronic image products. Images are produced from the best available original document. 


\title{
Development of Structural Materials Exhibiting Dielectric and Magnetic Loss at Radio Frequencies
}

Joseph R. Duke, Jr.*, Paul G. Apen, and Mark Hoisington (U. of Wash.)

\begin{abstract}
This is the final report of a one-year, Laboratory-Directed Research and Development (LDRD) project at the Los Alamos National Laboratory (LANL). The reduction of radio frequency (RF) return from military assets has been of critical interest for the last twenty years. New materials are required that not only provide a reduction in specular and travelling wave RF energy, but also function mechanically in primary structural applications. Typical radar attenuating material (RAM) is structurally parasitic and its utilization decreases the vehicle range by adding significant weight. New conducting and semiconducting polymers have demonstrated potential for RF absorption and can be incorporated into newly developed isotropic structural foams developed from laser target technology at LANL to absorb RF energy. Successful implementation of this technology will lead to broad-band absorbers, lightweight absorbers and radar-absorbing structures (RAS) that can be applied to existing aircraft or integrated into new designs. These new materials also show a high potential to be developed into "smart" structures, i.e., structures that adapt to the threat environment and optimize their absorption.
\end{abstract}

\section{Background and Research Objectives}

Stealthy technologies and their incorporation into low-density structural materials for military aircraft has been of critical interest to the Department of Defense (DoD) for the last twenty years. Materials that can provide benefits in aircraft performance, survivability, manufacturing, and costs in comparison to existing technologies are continually being evaluated by the DoD and it's contractors. The Polymers and Coatings Team of the

*Principal investigator, e-mail: jduke@lanl.gov 
Materials Science and Technology Division of LANL has been involved in the development of polymeric materials that are easily manufactured, can provide weight savings, and impart lowobservable properties to structural composite parts currently used in military aircraft.

In the late 1970s, LANL began to study the development of ultra-low density, microcellular foam materials for applications in weapons physics experiments. Techniques were developed to produce low density foam materials utilizing a high-internal-phase-emulsion (HIPE) polymerization process and LANL became a leader in HIPE foam technology [1-9]. The LANL foam process uses a high internal phase water-in-oil emulsion polymerization process based on modified crosslinked polystyrenes. In this process, an emulsion is created in which water is the internal phase comprising at least $75 \%$ by volume of the emulsion and water insoluble monomers comprise the remaining emulsion volume in the continuous oil phase. Free radical polymerization of the monomers in the emulsion state followed by removal of the water phase leads to the formation of a polymeric cellular material with cell sizes equivalent to the size of the water droplets in the emulsion. The large volume of water as the internal phase of the emulsion allows for the processing of ultra-low-density polymeric foams with isotropic mechanical properties. Foams with densities as low as $1 \mathrm{lb} / \mathrm{ft}^{3}$ and as high as $20 \mathrm{lb} / \mathrm{ft}^{3}$ have been prepared with this process.

Aerospace composite part fabrication is accomplished at both elevated temperatures and under pressure. The materials used in these parts have to be able to withstand both the processing and end use application conditions. Styrene/divinylbenzene foams produced using the early LANL techniques lacked thermal stability and mechanical properties at elevated temperatures. Our LDRD project focused on improving both the thermal and mechanical properties of HIPE-produced foams by changing their composition. Dynamic mechanical testing, thermogravimetric analysis, and mechanical testing were used to characterize the foams. The foam microstructures were probed with scanning electron microscopy.

Our research also focused on incorporating radar absorbing materials (RAM) into HIPE foams to improve their low-observable properties. Two techniques for incorporating RAM were investigated during this project. The first technique involved adding RAM to the emulsion prior to foam formation. The second technique involved adding RAM after foam fabrication. RF testing and conductivity measurements were used to evaluate both techniques of RAM loading.

In comparison to commercially available foams, this foam processing technique allows LANL foams to be homogeneous and tailorable over a broader range of density, microstructure, geometry, and composition. Commercially available foams can be manufactured with densities ranging from 3-22 lb/ft ${ }^{3}$, however the microstructure, geometry, and composition are not easily adjusted due to the extrusion or blow molding processes. The 
enhanced capabilities of the LANL foams provide significant advantages over the commercial foam systems and an increase in the number of possible military aircraft applications.

A major advantage of the LANL foam system is the near-net-shape processing capability. The LANL foam preparation process is ideal for near-net-shape casting because the foam precursor, a viscous emulsion, can be pumped or cast into molds of various geometries. Nearnet-shape casting capabilities of the LANL foam system also allow for the infiltration of the foam into honeycomb core. Plate shear testing of the foam-filled honeycomb samples was used to evaluate shear strength improvements over the properties of the individual honeycomb and foam components.

Honeycomb core crush is a common problem in the processing of composite sandwich panels. During the curing process of the sandwich structure, the anisotropic properties of the honeycomb core are unable to support the consolidation pressures and the edges of the sandwich panel are compacted or crushed. By filling the honeycomb core with a foam possessing isotropic mechanical properties, the consolidation pressures can be supported by the foam in the low strength honeycomb directions preventing the core crush problem. Potentially, if the mechanical performance of the foam systems can be significantly improved, a foam system could eventually be used to replace the honeycomb.

\section{Importance to LANL's Science and Technology Base and National R\&D Needs}

Los Alamos has a long history of cooperative efforts with the DoD and has vigorously pursued programs of interest to that agency. This project is consistent with these goals and has opened new areas of research and development for the Laboratory. The program focused our unique assets and capabilities on problems of national scope. The materials produced under this project are currently being evaluated by the US Airforce and its contractors for use in military aircraft. We worked closely with a DoD contractor on this technology and they have expressed a great deal of interest in its development. We provided them with samples for mechanical and RF testing for evaluation of this technology for program opportunities. Potential industrial collaborators and CRADA partners would include Boeing, Hughes, Teledyne Ryan, McDonnell Douglas, Sikorski, Northrop, General Atomic, and Lockheed. These technologies may also be of interest to the Department of the Navy for use in lowobservable radar towers and high-speed surface vessels. 


\section{Scientific Approach and Results to Date}

Composition and processing parameters of the HIPE technique were altered to obtain improvements over the physical and processing properties of the styrene/divinylbenzene foams produced for weapons experiments and for commercial foams. Three major accomplishments were realized through this research. First, polymeric foams with improved thermal, mechanical, and structural properties over commercial foam materials were obtained. Second, processes for filling molds of various geometries and for filling honeycomb materials for sandwich panels with these foams were developed. Finally, HIPE foams were modified with RAM for low observable applications. Figure 1 shows scanning electron micrographs of both commercial and HIPE foams. The HIPE foam is much more uniform in terms of cell size, it is open-celled, and can be processed more easily than the commercial foam. The open-celled property allows for the post-treatment of the foam with RAM.

Mechanical properties of foams and foam-filled honeycombs were evaluated as a function of foam density for both styrene/divinylbenzene and compositionally altered foams. Figure 2 shows the results of compression tests on both types of foams as a function of foam density. Postcured styrene divinylbenzene foams have compressive strengths of over $300 \mathrm{lb} / \mathrm{in}^{2}$ at densities of $10 \mathrm{lb} / \mathrm{ft}^{3}$. The modified foams are expected to exceed this value with further improvements in processing. This compressive strength exceeds requirements for composite part fabrication for aerospace applications. Figure 3 depicts the synergistic improvements in shear properties obtained by adding the styrene/divinylbenzene HIPE foam to honeycomb. These results indicate that the foam-filled honeycomb will have improved impact and mechanical properties over honeycomb alone. The processing problem of honeycomb core crush would also be minimized.

Thermal properties of these foams were improved by altering the composition of the oil used in the preparation of the HIPE. Various maleimides were used to increase both the thermal stability and glass transition temperature of these foams. Figure 4 shows how increasing maleimide concentration increases the foams glass transition temperature with a low temperature crosslinker. Figure 5 shows how the storage modulus at lower temperatures is improved by adding more maleimide with a higher temperature crosslinker. Figure 6 shows how the glass transition temperature is dependent on crosslink density. The ideal thermal properties of the system would be realized in a perfectly alternating styrene/maleimide copolymer. The higher the crosslink density the more brittle the material becomes. The important point in these three figures is that the foam's thermal properties can be tailored for a specific temperature requirement. Typical composite part fabrication is accomplished at temperatures near $177^{\circ} \mathrm{C}$. Glass transition temperatures of these foams can exceed $290^{\circ} \mathrm{C}$. 
RAM in the form of fibers were incorporated into these foams during emulsification; the fibers uniformly filled the foam. The RAM-filled emulsion was then infused into honeycomb, cured and tested for RF absorption. The fiber-filled foam performed successfully as a lowobservable material. RAM was also added to foams in the form of a conductive polymer. The $\mathrm{RF}$ response of these materials spanned the useful range of properties for bulk absorbers (stealthy materials). Conductivity measurements of the polymeric RAM are shown in Figure 7 and illustrate how well the conductive properties can be controlled by our method of RAM infiltration.

In summation, polymeric foam systems have been produced under this LDRD project that meet both the thermal and mechanical requirements of the US Airforce and its contractors for composite part fabrication. These foams have been incorporated into honeycombs and have been modified for low-observable properties with RAMs. The materials are useful for the production of low-density polymeric composite parts for aircraft applications.

\section{References}

1. Williams, J. M., "Toroidal Microstructures From Water-in-Oil Emulsions," Langmuir, 4, 44 (1988).

2. Williams, J. M. and D. A. Wrobleski, "Spatial Distribution of the Phases in Water-in-Oil Emulsions: Open and Closed Microcellular Foams From Cross-Linked Polystyrene," Langmuir, 4, 656 (1988).

3. Williams, J. M. and D. A. Wrobleski, "Microstructures and Properties of Some Microcellular Foams," Journal of Materials Science Letters, 24, 4062 (1989).

4. Nyitray, A. M. and J. M. Williams, "Microcellular Composite Foams," Journal of Cellular Plastics, 25, 217 (1989).

5. Williams, J. M., A. J. Gray, and M. H. Wilkerson, "Emulsion Stability and Rigid Foams From Styrene or Divinylbenzene Water-in-Oil Emulsions," Langmuir, 6, 437 (1990).

6. Williams, J. M. and M. H. Wilkerson, "High-density Foams Prepared With the StyreneDivinylbenzene Copolymer/Heptane System," Polymer, 31, 2162 (1990).

7. Williams, J. M., A. M. Nyitray, and M. H. Wilkerson, "Composite Foams," US Patent 4,966,919 (1990).

8. Williams, J. M., "High Internal Phase Water-in-Oil Emulsions: Influence of Surfactants and Cosurfactants on Emulsion Stability and Foam Quality," Langmuir, 7, 1370 (1991).

9. Williams, J. M., A. M. Nyitray, and M. H. Wilkerson, "Composite Foams," US Patent $5,037,859$ (1991). 


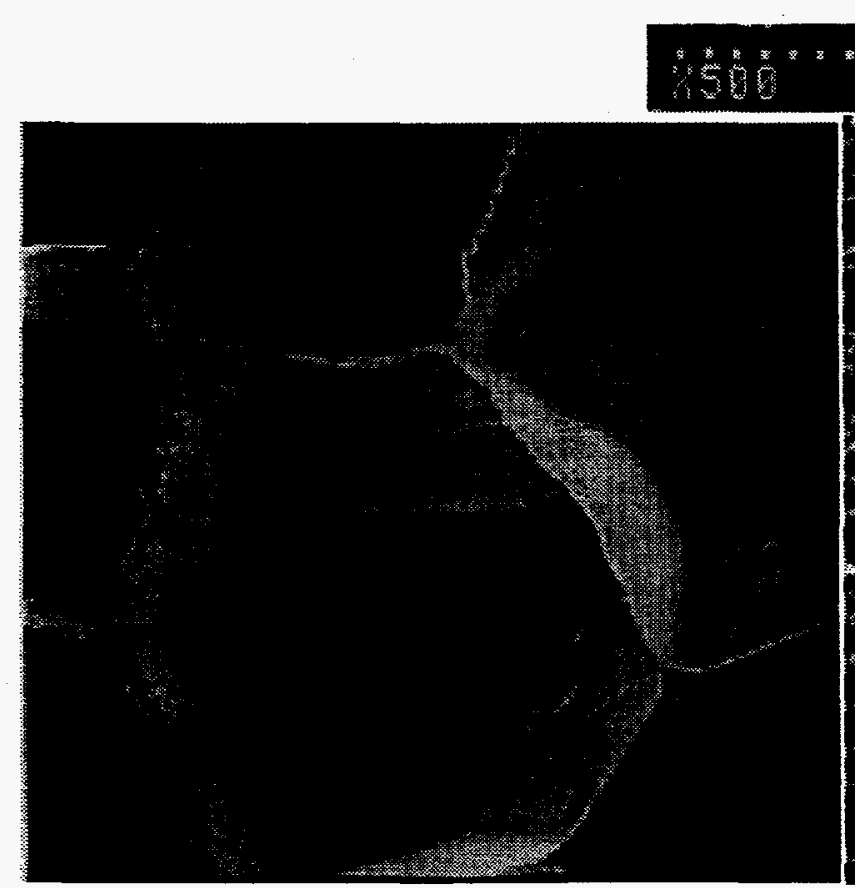

Blown Foam

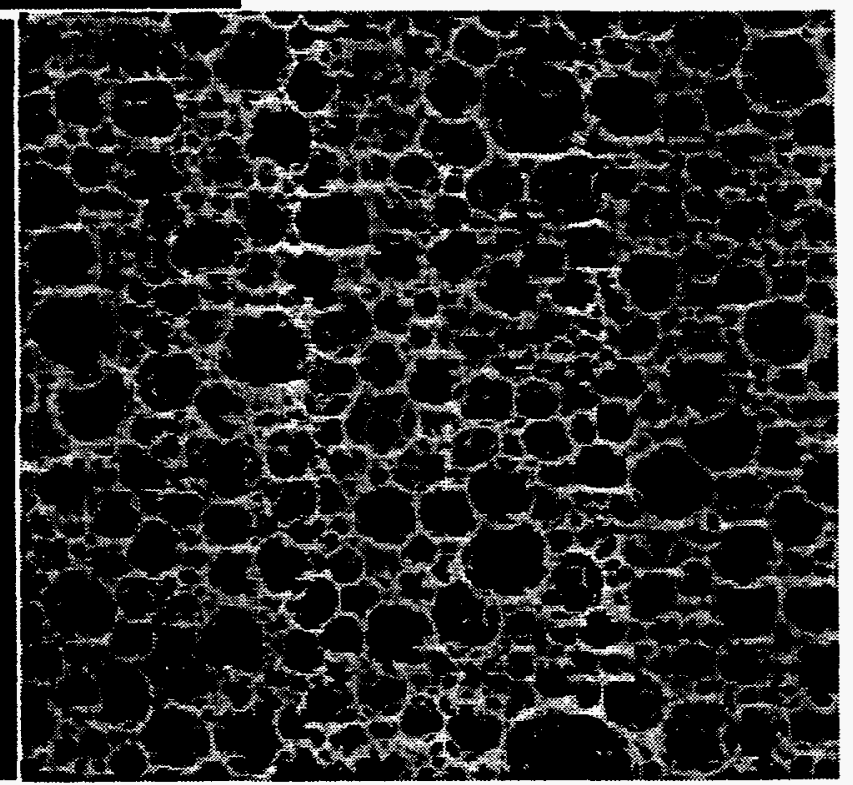

HIPE Foam

Figure 1. Scanning electron microscopy (SEM) photomicrograph comparison of commercial blown foam with LANL high internal phase emulsion foam.

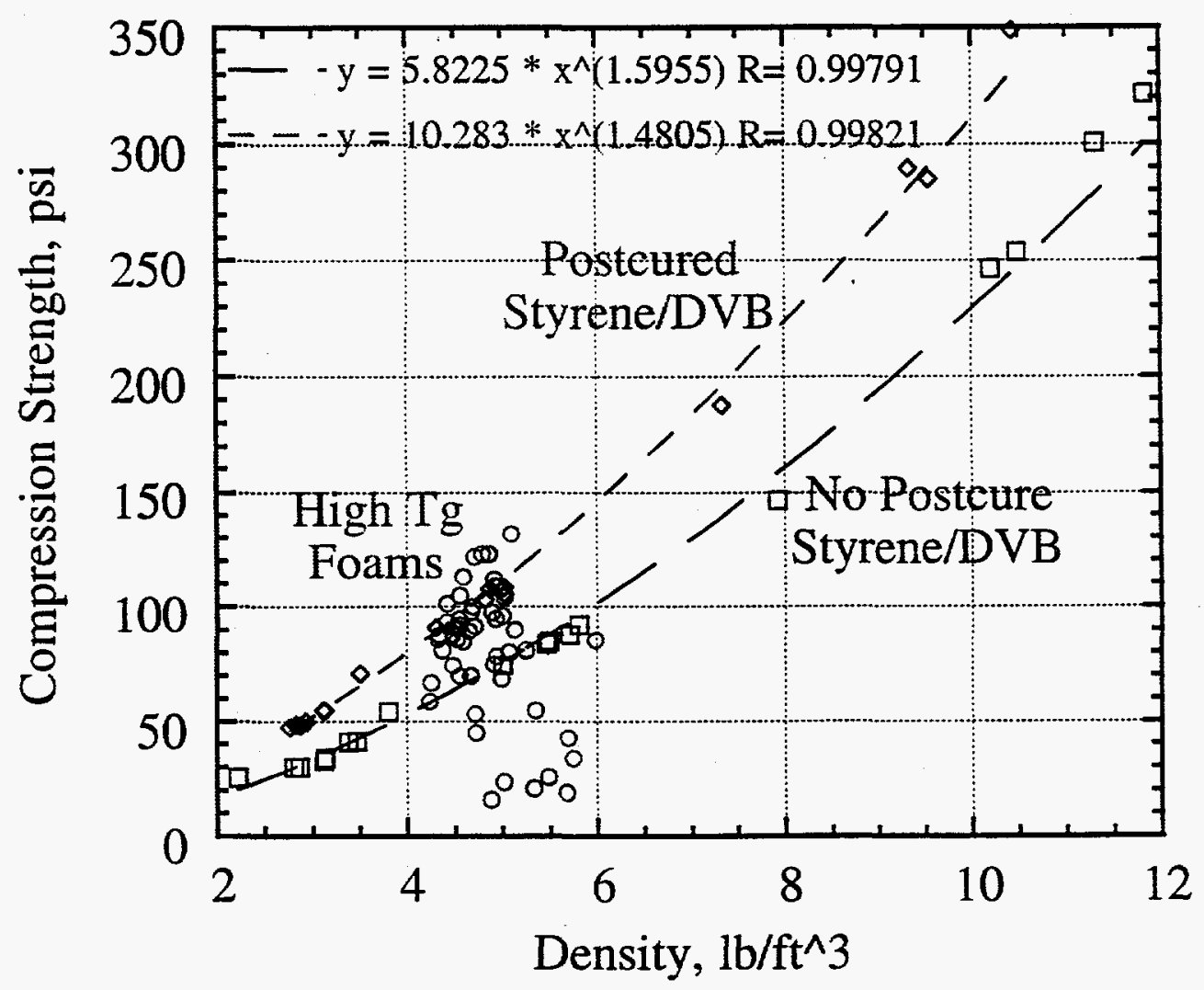

Figure 2. Compression strengths of high internal phase emulsion foams. 


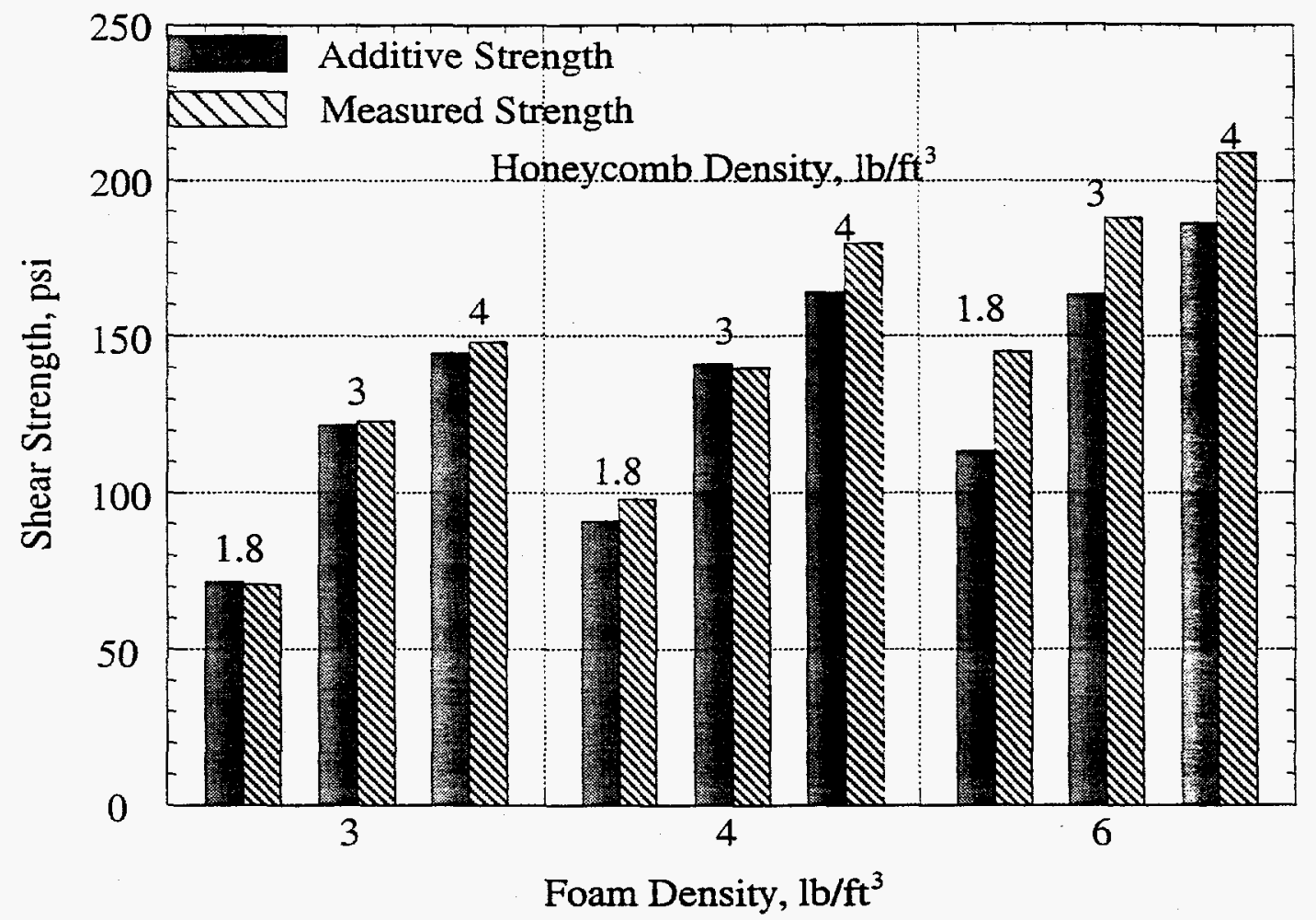

Figure 3. Shear strengths of high internal phase foam filled honeycombs.

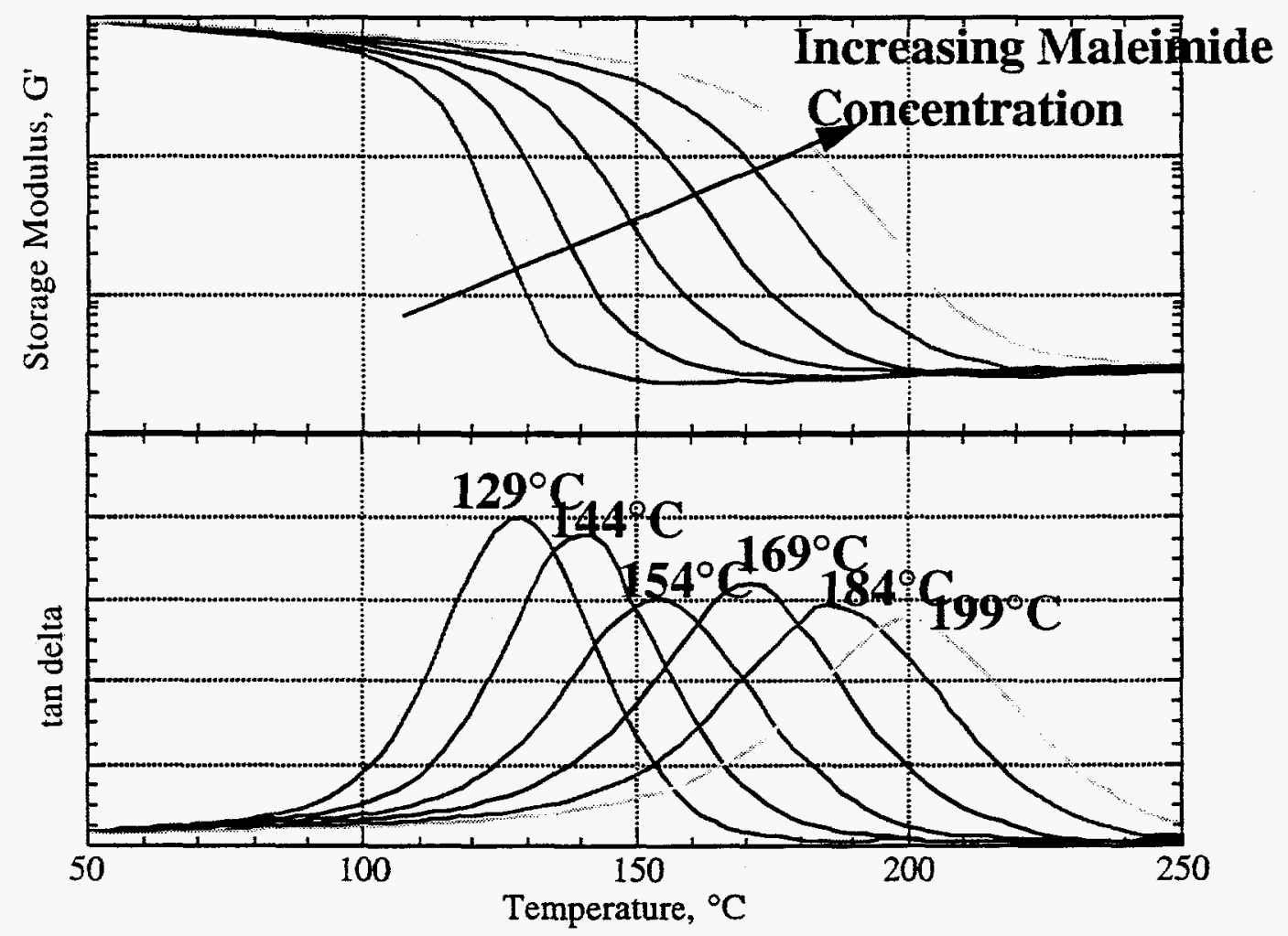

Figure 4. Dynamic mechanical analysis of high temperature foams with increasing maleimide concentration and a low temperature crosslinker. 


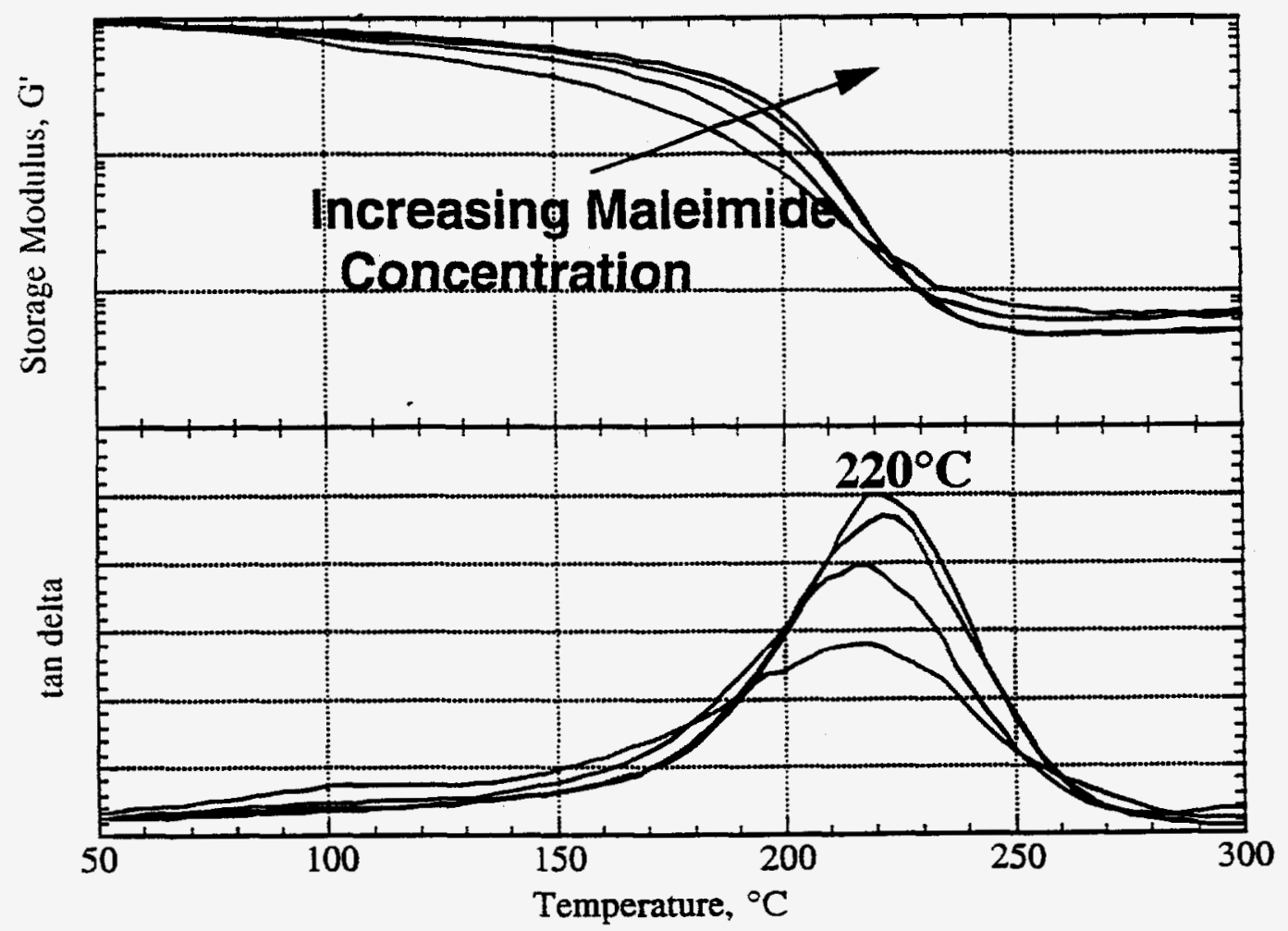

Figure 5. Dynamic mechanical analysis of high temperature foams with increasing maleimide concentration and a high temperature crosslinker.

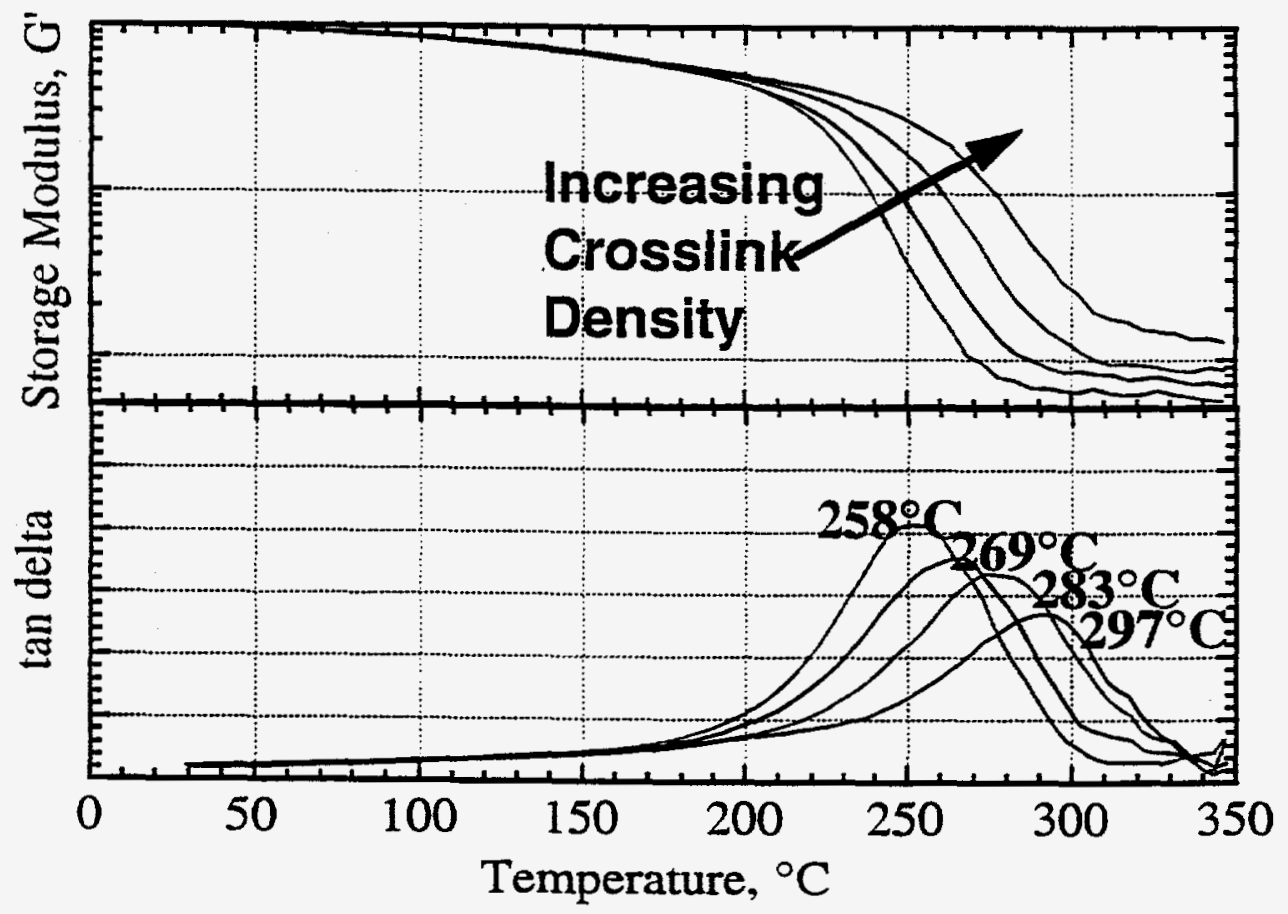

Figure 6. Dynamic mechanical analysis of high temperature foams with increasing crosslinking density. 


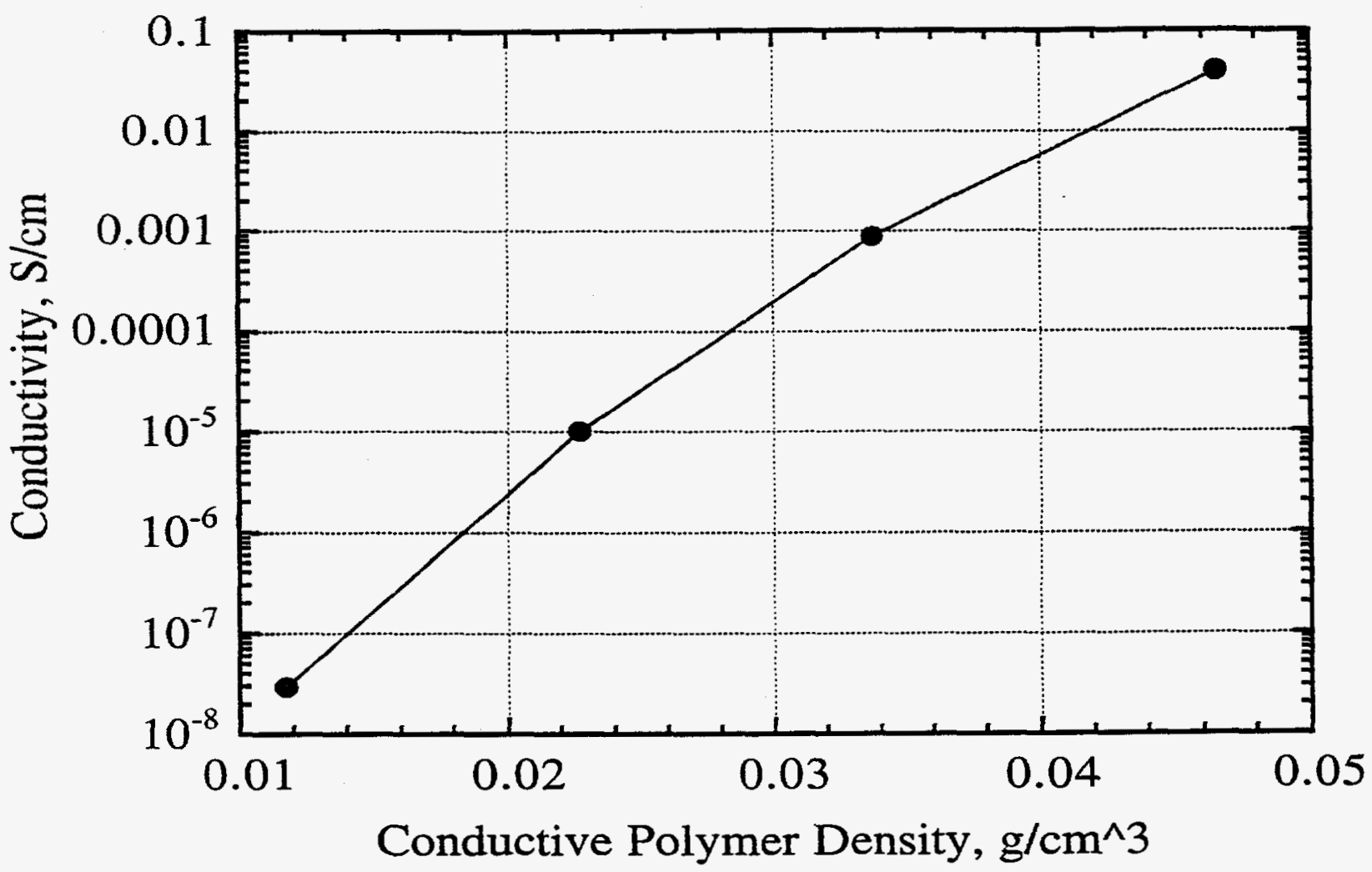

Figure 7. Conductivity of structural conductive foams as a function of the conductive polymer densities in the final foam system. 